\title{
Promotion of Selective Pathways in Isomerizing Functionalization of Plant Oils by Rigid Framework Substituents
}

\author{
Josefine T. Christl, ${ }^{[\mathrm{a}]}$ Philipp Roesle, ${ }^{[\mathrm{a}]}$ Florian Stempfle, ${ }^{[\mathrm{a}]}$ Gerhard Müller, ${ }^{[\mathrm{a}]}$ Lucia Caporaso, $^{*[\mathrm{~b}]}$ \\ Luigi Cavallo, ${ }^{[c]}$ and Stefan Mecking*[a]
}

The 1,2-( $\left(\mathrm{CH}_{2} \mathrm{P}(1 \text {-adamantyl })_{2}\right)_{2} \mathrm{C}_{6} \mathrm{H}_{4}$ (dadpx) coordinated palladium complex [(dadpx)Pd(OTf $\left.)_{2}\right]$ (1) is a catalyst precursor for the isomerizing methoxycarbonylation of the internal double bond of methyl oleate, with an unprecedented selectivity ( $96 \%)$ for the linear diester 1,19-dimethyl nonadecanedioate. Rapid formation of the catalytically active solvent-coordinated hydride species $[(\text { dadpx }) \mathrm{PdH}(\mathrm{MeOH})]^{+}(3-\mathrm{MeOH})$ is evidenced by NMR spectroscopy, and further isolation and $\mathrm{X}$-ray crystal structure analysis of $\left[(\text { dadpx }) \mathrm{PdH}\left(\mathrm{PPh}_{3}\right)\right]^{+}\left(3-\mathrm{PPh}_{3}\right)$. DFT calculations of key steps of the catalytic cycle unravel methanolysis as the decisive step for enhanced selectivity and the influence of the rigid adamantyl framework on this step by destabilization of transition states of unselective pathways.

\section{Introduction}

The use of renewable resources as a source of chemicals requires their efficient transformation to useful building blocks. Fatty acids are attractive feedstocks due to their long-chain methylene sequences. ${ }^{[1]}$ Their incorporation into linear longchain $\alpha, \omega$-functionalized compounds is of interest for example for the generation of semi-crystalline aliphatic polyesters, ${ }^{[2]}$ hydrophobic polyamides, ${ }^{[2 b]}$ and hydrolytically degradable poly-

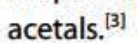

However, the terminal functionalization of fatty acids is a synthetic challenge. Biotechnological, ${ }^{[4]}$ as well as entirely chemical approaches $^{[1 \mathrm{~b}, 5]}$ are studied to this end. Self-metathesis ${ }^{[1 \mathrm{~b}, 5 \mathrm{a}]}$ of oleates can yield 1,18-octadecandioates (after subsequent hydrogenation of the double bond). However, stoichiometric amounts of the $C_{18}$-alkene are formed. Also, as an equilibrium reaction only $50 \%$ conversion can be attained unless the product can be removed from the reaction mixture selectively.

By contrast, selective isomerization/functionalization approaches in principle can incorporate the entire fatty acid chain. This is particularly difficult, however, as terminal olefins

\footnotetext{
[a] J. T. Christl, P. Roesle, F. Stempfle, Prof. Dr. G. Müller, Prof. Dr. S. Mecking Department of Chemistry

University of Konstanz

78464 Konstanz (Germany)

Fax: $(+49) 7531885152$

E mail: stefan.mecking@uni konstanz.de

[b] Prof. Dr. L Caporaso

Department of Chemistry

University of Salerno

84084 Fisciano (SA) (Italy)

E mail: Icaporaso@unisa.it

[c] Prof. Dr. L Cavallo

King Abdullah University of Science and Technology

Thuwal 239556900 (Saudi Arabia)
}

are thermodynamically strongly disfavored versus the internal double bonds of the substrate. The state of the art of isomerization/functionalization in terms of terminal selectivity and a lack of other undesired side reactions like olefin hydrogenation or further reactions of the products is isomerizing alkoxycarbonylation. This remarkable reaction fully incorporates an unsaturated fatty acid starting material into an $\alpha, \omega$-diester. In this reaction, palladium(II) catalysts modified with the diphosphine 1,2-( $\left(\mathrm{CH}_{2} \mathrm{PtBu}_{2}\right)_{2} \mathrm{C}_{6} \mathrm{H}_{4}$ (dtbpx) $)^{[6]}$ convert the double bond deep in the chain of unsaturated fatty acids to a terminal ester group with high selectivity (Scheme 1). ${ }^{[2 a, 7,8]}$

The catalyst precursor of choice to date is [(dtbpx)Pd(OTf $\left.)_{2}\right]$ 2 (Figure 1) which yields the linear diester in $90 \%$ selectivity. The remaining branched side products are formed by $\mathrm{CO}$ inser-

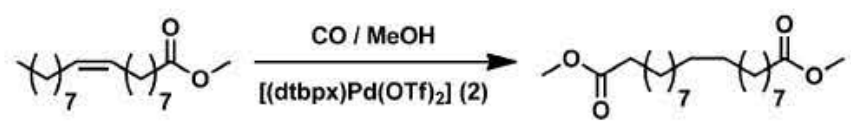

Scheme 1. Isomerizing methoxycarbonylation of methyl oleate.

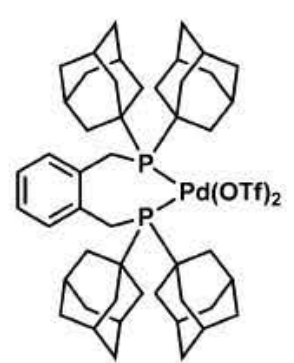

[(dadpx)Pd(OTf) $]$ (1)

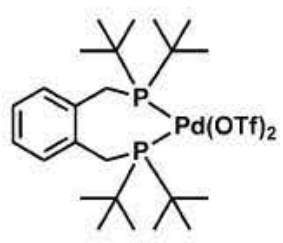

[(dtbpx)Pd(OTf) $]$ (2)
Figure 1. Chemical structure of the novel complex 1 and benchmark catalyst precursor 2. 
tion into secondary alkyls all along the fatty acid chain, and their methanolysis as the rate determining step. This high kinetic preference for the desired linear product is a result of the high steric bulk of the phosphines' tert-butyl substituents (as reflected by an opening angle at the metal center left open by the diphosphine of only $\left.172^{\circ}\right)^{[15]}$ which enhances methanolysis and provides an increased difference in barrier $\left(\Delta \Delta G^{\prime}\right)$ between methanolysis of the linear and branched acyl. ${ }^{[9]}$

With this picture, a necessary improvement of selectivity to reduce formation of branched side products is difficult to envision as tert-butyl groups already represent an upper limit of steric congestion imposed upon the metal center. We now show this limitation can be overcome by rigid framework adamantyl substituents that do not provide a further congestion per se at the metal center, but interact specifically and at a rather remote position to the metal center in the transition states of methanolysis.

\section{Results and Discussion}

Adamantylphosphines have been studied as ligands for various catalytic transformations, most prominently cross coupling reactions. ${ }^{[10,11 \mathrm{c}-\mathrm{d}]}$ A general advantage of adamantyl versus tertbutyl substituents on phosphorus is considered to be a higher stability ${ }^{[11]}$ both in terms of handling of the catalyst precursors and during catalysis. We prepared the diphosphine 1,2$\left(\mathrm{CH}_{2} \mathrm{P}(1 \text {-adamantyl })_{2}\right)_{2} \mathrm{C}_{6} \mathrm{H}_{4}$ (dadpx) according to a reported procedure ${ }^{[12]}$ by lithiation of the borane di(1-adamantyl)phosphine adduct and subsequent addition of $\alpha, \alpha^{\prime}$-dichloro-o-xylene. The resulting borane diphosphine complex was treated with $\mathrm{HBF}_{4}$ to yield 1,2-( $\left(\mathrm{CH}_{2} \mathrm{P}(1 \text {-adamantyl })_{2}\right)_{2} \mathrm{C}_{6} \mathrm{H}_{4}$ (dadpx) as a colorless solid which was recrystallized from $\mathrm{EtOH} / \mathrm{CH}_{2} \mathrm{Cl}_{2}$. The diphosphine was reacted with $\left[\mathrm{Pd}(\mathrm{dba})_{2}\right]$ ( $\mathrm{dba}=$ dibenzylideneacetone) to form $[(d a d p x) P d(d b a)]$ which was oxidized with benzoquinone in the presence of triflic acid to afford the novel complex $\left[(\right.$ dadpx $\left.) \mathrm{Pd}(\mathrm{OTf})_{2}\right](\mathbf{1})$ in $78 \%$ yield (for detailed experimental procedures see the Supporting Information).

The catalytic properties of 1 in the isomerizing methoxycarbonylation of methyl oleate (MO) were evaluated at different $\mathrm{CO}$ pressures, temperatures, and reaction times using a smallscale $20 \mathrm{~mL}$ stainless steel autoclave. For comparison, carbonylations with 2 were run back-to-back under identical conditions (Table 1). In order to study "real-life" catalytic performance, technical grade high oleic sunflower oil methyl ester (Dakolub MB $9001{ }^{[13]}$ methyl oleate content of $92.5 \%$ ) was used, rather than highly purified methyl oleate. A maximum conversion is obtained at $90^{\circ} \mathrm{C}$ (entries 1-3). At a lower temperature, the reaction is slower, and at an elevated temperature of $110^{\circ} \mathrm{C}$, presumably catalyst decomposition results in a lower overall conversion. Conversion increases with $\mathrm{CO}$ pressure in the regime studied, 5 to 40 bar (entries 2, 7, 8 and 9). Beyond 20 bar, the effect of $\mathrm{CO}$ pressure is low.

Remarkably, the selectivity for the linear diester with 1 is significantly higher than the state-of-the art with $\mathbf{2}$ under all conditions. Up to $96 \%$ selectivity is observed. Essentially, in comparison to 2, the amount of undesired branched side products is reduced to half. Selectivities are relatively insensitive to reaction conditions. In detail, selectivity decreases slightly with reaction temperature, as expected from Eyring's relationship. CO pressure virtually does not affect the selectivity with 1 . As the major side product, the methyl-branched diester (B1) resulting from $\mathrm{CO}$ insertion and subsequent methanolysis at the $\mathrm{C}$-atom adjacent to the terminus of the methyl oleate (MO) chain is formed in all cases. A much smaller amount of the ethyl branched side product (B2) and all higher branched $C_{19}$ diesters are formed (B3 to B16; for details of analysis see Ref. [15]).

To study the course of the reaction over time, carbonylations were carried out in a $200 \mathrm{~mL}$ pressure reactor equipped with a sampling valve at the bottom of the reactor (for details see the Supporting Information). Samples were drawn periodically,

\begin{tabular}{|c|c|c|c|c|c|c|c|c|c|c|c|c|}
\hline Entry & Complex & $\begin{array}{l}t \\
{[\mathrm{~h}]}\end{array}$ & $\begin{array}{l}T \\
{\left[{ }^{\circ} \mathrm{C}\right]}\end{array}$ & $p(\mathrm{CO})[\mathrm{bar}]$ & $\begin{array}{l}\text { Conversion } \\
\text { of } \mathrm{MO}[\%]\end{array}$ & $\begin{array}{l}\text { Selectivity towards } \\
1,19 \text { diester }[\%]\end{array}$ & 1,19 diester [\%] & $\begin{array}{l}\text { Branched } \\
\text { products }^{[b]}[\%]\end{array}$ & $\begin{array}{l}\mathrm{B} 1^{[\mathrm{b}]} \\
{[\%]}\end{array}$ & $\begin{array}{l}\mathrm{B} 2^{[\mathrm{b}]} \\
{[\%]}\end{array}$ & $\begin{array}{l}\mathrm{B}^{[\mathrm{b}]} \\
{[\%]}\end{array}$ & $\begin{array}{l}\text { B4 B16 }{ }^{[\mathrm{b}]} \\
{[\%]}\end{array}$ \\
\hline 1 & 1 & 18 & 70 & 20 & 39.1 & 95.7 & 37.4 & 1.7 & 42 & 10 & 4 & 44 \\
\hline 2 & 1 & 18 & 90 & 20 & 46.1 & 95.4 & 44.0 & 2.1 & 52 & 9 & 5 & 34 \\
\hline 3 & 1 & 18 & 110 & 20 & 25.1 & 94.0 & 23.6 & 1.5 & 54 & 8 & 5 & 33 \\
\hline 4 & 2 & 18 & 70 & 20 & 85.0 & 92.2 & 78.4 & 6.6 & 33 & 10 & 5 & 52 \\
\hline 5 & 2 & 18 & 90 & 20 & 94.8 & 90.6 & 85.9 & 8.9 & 34 & 9 & 5 & 52 \\
\hline 6 & 2 & 18 & 110 & 20 & 74.3 & 87.5 & 65.0 & 9.3 & 37 & 8 & 5 & 50 \\
\hline 7 & 1 & 18 & 90 & 5 & 34.0 & 95.9 & 32.6 & 1.4 & 51 & 11 & 5 & 33 \\
\hline 8 & 1 & 18 & 90 & 10 & 38.4 & 95.6 & 36.7 & 1.7 & 52 & 10 & 5 & 33 \\
\hline 9 & 1 & 18 & 90 & 40 & 48.7 & 95.9 & 46.7 & 2.0 & 50 & 11 & 5 & 34 \\
\hline 10 & 2 & 18 & 90 & 5 & 74.0 & 91.6 & 67.8 & 6.2 & 36 & 10 & 6 & 48 \\
\hline 11 & 2 & 18 & 90 & 10 & 91.0 & 91.0 & 82.8 & 8.2 & 35 & 9 & 5 & 51 \\
\hline 12 & 2 & 18 & 90 & 40 & 96.7 & 90.2 & 87.2 & 9.5 & 33 & 9 & 5 & 53 \\
\hline
\end{tabular}




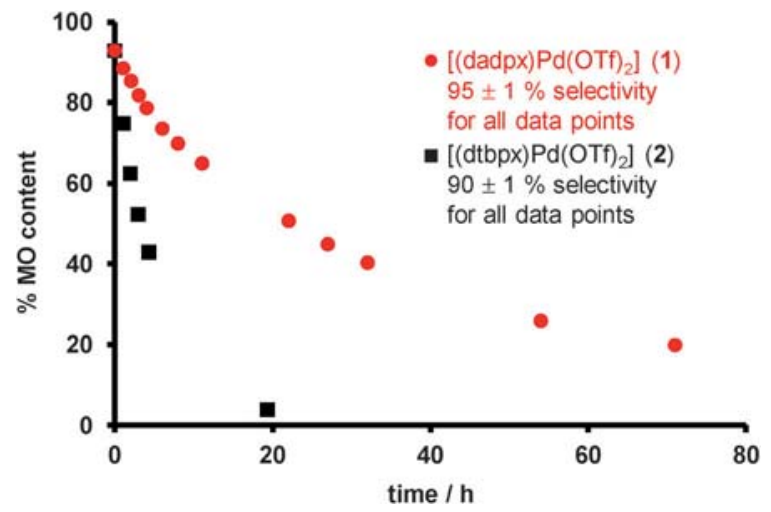

Figure 2. Time dependency of methyl oleate conversion with catalyst pre cursors 1 and 2. Reaction conditions: $n(\mathrm{Pd})=0.77 \mathrm{mmol}, 32.5 \mathrm{~mL}$ high oleic sunflower oil methyl ester ( $92.5 \% \mathrm{MO}), 140 \mathrm{~mL} \mathrm{MeOH}, 20$ bar CO, $90^{\circ} \mathrm{C}$.

and analyzed. The reaction with $\mathbf{1}$ is slower vs. $\mathbf{2}$, but catalysis proceeds over prolonged periods of time and, after $120 \mathrm{~h}$, virtually complete conversion can be achieved with uncompromised selectivity (entry 13 and Figure 2).

In order to elucidate whether the slower conversion is due to a slower transformation of the catalyst precursor to the active species, the activation of 1 was studied. 1 was dissolved in a mixture of $\mathrm{CD}_{2} \mathrm{Cl}_{2} / \mathrm{MeOH}$ ( $3 / 2$ by volume) and ${ }^{1} \mathrm{H}$ and ${ }^{31} \mathrm{P}\left\{{ }^{1} \mathrm{H}\right\}$ NMR spectra were recorded. Complete conversion to a solvent-coordinated hydride species [(dadpx) $\mathrm{PdH}(\mathrm{MeOH})]^{+}$ (3-MeOH) occurred within $5 \mathrm{~min}$ at room temperature as evidenced by disappearance of the ${ }^{31} \mathrm{P}$ signal of 1 at $74.3 \mathrm{ppm}$ and the appearance of a broad singlet at $73.2 \mathrm{ppm}$ and a doublet at $17.4 \mathrm{ppm}$ with a coupling constant of ${ }^{2} J_{\mathrm{PP}}=16.1 \mathrm{~Hz}$ for the two inequivalent phosphorous atoms. Hydride formation is further evidenced by a ${ }^{1} \mathrm{H}$ NMR signal at $10.82 \mathrm{ppm}$ (doublet of doublet with ${ }^{2} J_{\text {PHtrans }}=177.9 \mathrm{~Hz}$ and ${ }^{2} J_{\text {PHcis }}=23.5 \mathrm{~Hz}$ ). In order to enable isolation of the hydride complex for a further confirmation of its identity, stronger coordinating $\mathrm{PPh}_{3}$ was added to the aforementioned solution of 3-MeOH for stabilization, resulting in the formation of $\left[(\text { dadpx }) \mathrm{PdH}\left(\mathrm{PPh}_{3}\right)\right]^{+}\left(3-\mathrm{PPh}_{\mathbf{3}}\right)$ as evidenced by its ${ }^{31} \mathrm{P}$ and ${ }^{1} \mathrm{H}$ NMR spectra (Figure 3, and $\mathrm{SI}$ ). ${ }^{[14]}$ 3-PPh ${ }_{3}$ was isolated by extraction of the methanol solution with pentane, yielding large red crystals suitable for X-ray diffraction (Figure 4). Analysis of the $X$ ray crystal structure revealed that bond lengths and angles (see the Supporting Information) of $3-\mathrm{PPh}_{3}$ are in the typical range for this type of complexes. $\mathrm{Pd} \mathrm{H}$ bond lengths of $3-\mathrm{PPh}_{3}$ $(d(\mathrm{Pd}-\mathrm{H})=1.57 \quad(9) \AA)$ and the tert-butyl analogue $(d(\mathrm{Pd}-\mathrm{H})=$ 1.59 (9) $\AA$ ) are virtually identical.
The opening angles of $3-\mathrm{PPh}_{3}\left(176^{\circ}\right)$ and its tert-butyl analogue $\mathrm{e}^{[15]}\left(172^{\circ}\right)$ are very similar and indicate a comparable steric bulk of the adamantyl- and the tert-butyl substituted diphosphine, with the adamantyl-substituted diphosphine actually being slightly less sterically congesting. In summary, $\mathbf{1}$ is converted to a catalytically active species very efficiently. This also suggests that the slower conversion of methyl oleate under pressure reactor conditions with 1 vs. 2 is due to an intrinsically slower alkoxycarbonylation (vide infra).

These findings raise the question of the origin of the extraordinary selectivity observed with 1 . DFT calculations on the $\mathrm{CO}$ insertion reaction and the subsequent methanolysis reaction on the linear and the methyl branched Pd-alkyl species were performed for complexes with both diphosphines (for details see the Supporting Information). For all the reactions studied, CO insertion is feasible and the linear Pd-acyl product is the lowest in energy, being about $10 \mathrm{kcal} \mathrm{mol}^{-1}$ more stable relative to the corresponding Pd-alkyl starting material, and about $1 \mathrm{kcal} \mathrm{mol}^{-1}$ more stable than the branched Pd-acyl species, in terms of $\Delta G$. The methanolysis of the Pd-acyl species is rate limiting for both systems. As found previously for $\mathrm{dtbpx}_{1}{ }^{[9]}$ the methanolysis reaction pathway via a cluster of three $\mathrm{MeOH}$ molecules is favored for the linear Pd-acyl species (Figure 5, a and c) while for the case of the more hindered branched Pdacyl species the reaction pathway with a single $\mathrm{MeOH}$ molecule is lower in energy (Figure 5, b and d).

As expected, for both diphosphines the most favored methanolysis transition state involves the linear Pd-acyl species. The transition states (TS) for methanolysis of both the linear and the branched species are higher for the adamantyl-diphosphine due to unfavorable steric interactions of the methanol molecules involved in this TS with the $\mathrm{CH}_{2}$ groups of the adamantyl distal of the Pd center (corresponding to a "second coordination sphere" in terms of distance from the metal center). In fact, this interaction hinders the three-MeOH molecule clus-

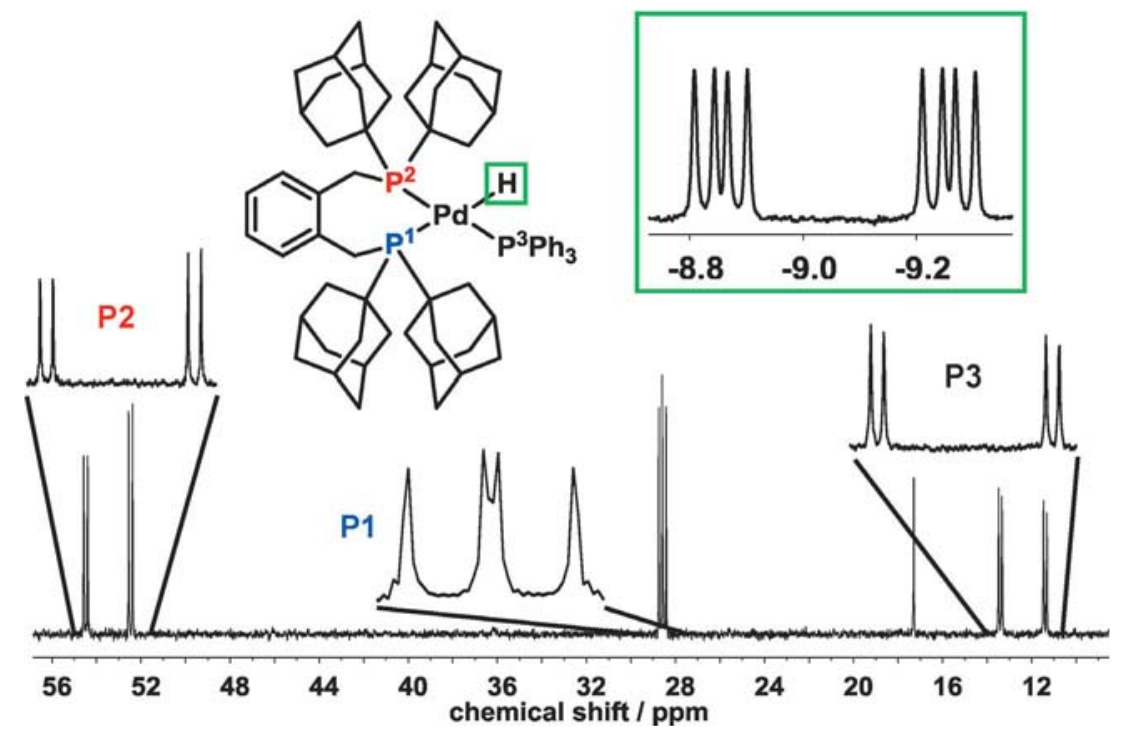

Figure 3. ${ }^{31} \mathrm{P}\left\{{ }^{1} \mathrm{H}\right\}$ NMR spectrum of $3 \mathrm{PPh}_{3}$ formed in situ by dissolving 1 in $\mathrm{CD}_{2} \mathrm{Cl}_{2} / \mathrm{MeOH}$ (3:2 by volume) and ad dition of 1 equiv. $\mathrm{PPh}_{3}$ at $25^{\circ} \mathrm{C}$. Insert: hydride region of ${ }^{1} \mathrm{H}$ NMR. 


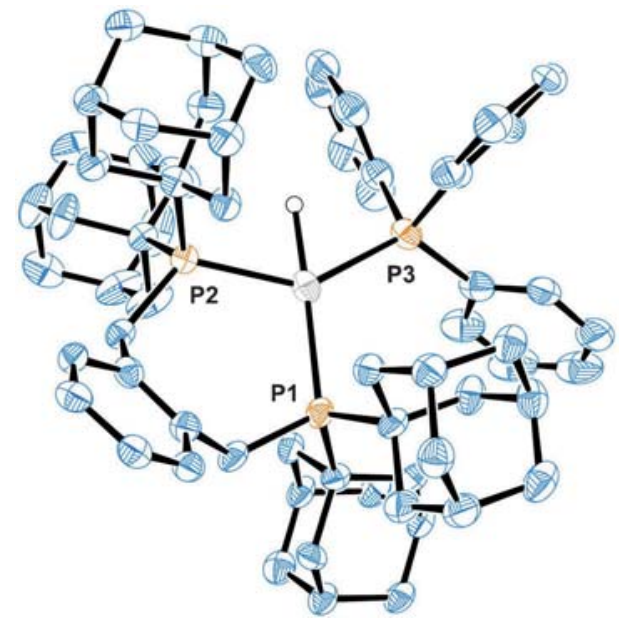

Figure 4. $X$ ray crystal structure of $\mathbf{3} \mathbf{P P h}_{3}$. Hydrogen atoms (except $\mathrm{Pd} \mathrm{H}$ ), the non coordinating triflate counterion, and an interstitial methanol mole cule were omitted for clarity. Displacement ellipsoids are shown at the $50 \%$ probability level.

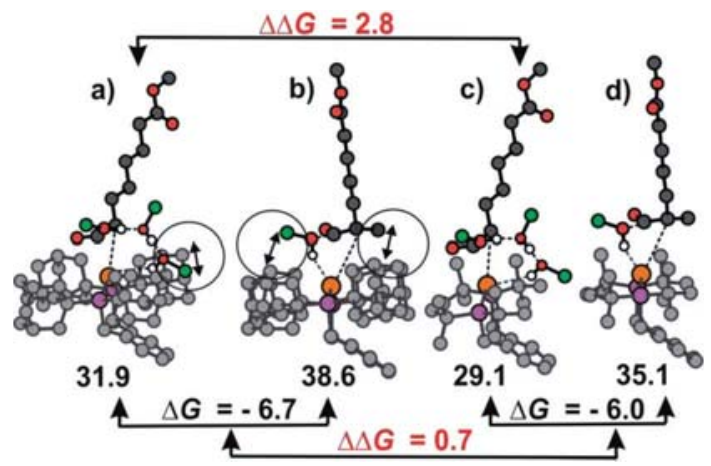

Figure 5. Transition states of methanolysis of linear $(a, c)$ versus methyl branched (b, d) Pd acyl species with the adamantyl (a, b) and tert butyl (c, d) substituted diphosphine. Activation free energies, $\Delta G$ in $\mathrm{kcal} \mathrm{mol}{ }^{1}$, are rela tive to the corresponding Pd acyl species. Unfavorable steric interactions of substrate and ligand are highlighted by a circle. For the sake of readability, the $\mathrm{C}$ atom of $\mathrm{MeOH}$ is colored in green.

ter in assisting the reaction, such that the favored methanolysis TS is about $3 \mathrm{kcal} \mathrm{mol}^{-1}$ higher for the catalyst formed from 1 than from 2 (compare Figure 5, a and c), in agreement with the experimentally observed slower ester formation reaction for 1 vs. 2. Most decisively, the energy difference between the linear and the branched Pd-acyl methanolysis transition states is more pronounced with 1 than 2. Due to steric interactions involving the methyl branch and the $\mathrm{MeOH}$ molecule with the adamantyl framework, the preference toward the linear diester product is about $1 \mathrm{kcalmol}^{-1}$ higher with 1 than with 2 (in Figure 5, compare $a$ and $b$ with $c$ and $d$, respectively). This trend agrees with the experimentally found higher selectivity for 1 vs. 2.

\section{Conclusions}

The double bond deep in the fatty acid chain of methyl oleate can be converted to a terminal ester group with a selectivity of $96 \%$. Such an isomerization/functionalization selectivity is not only unprecedented, ${ }^{[5 b, 16]}$ but also practically important in that it reduces the amount of undesired side products to half in comparison to the state of the art. It even matches successful approaches for the terminal functionalization of 2-olefins, ${ }^{[16 b, 17]}$ though here the double bond is in direct vicinity to the targeted chain terminus. The combined experimental and theoretical approach pursued here provides evidence for the origin of the observed effect. By comparison to the established tert-butyl substituted catalyst, steric congestion at the metal center is not increased. Rather, the rigid nature of the adamantyl substituents results in a specific interaction with the methanol substrate relatively remote to the metal center, which destabilizes the transition states of unselective pathways. To our knowledge, this is also the first example of an understanding of different selectivities with adamantylphosphines in catalysis in general. The underlying principle of a specific interaction of the rather remote adamantyl framework with the substrate may be inspiring for a rational development of other catalytic reactions employing adamantyl-substituted ligands as well.

\section{Experimental Section}

Detailed experimental procedures, NMR spectra, characterization, computational details, and crystallographic details of $3-\mathrm{PPh}_{3}$ (CCDC 992440), are available in the Supporting information.

\section{Acknowledgements}

Financing by the Stiftung Baden-Württemberg (Programm Umwelttechnologieforschung, U14) is acknowledged. P.R. gratefully acknowledges support from the Carl-Zeiss-Foundation by a graduate fellowship. Donation of high oleic sunflower oil methyl ester by Dako AG is acknowledged.

Keywords: carbonylation • catalysis • isomerization renewable resources $\cdot$ selectivity

[1] a) U. Biermann, U. Bornscheuer, M. A. R. Meier, J. O. Metzger, H. J. Schä fer, Angew. Chem. Int. Ed. 2011, 50, 3854 3871; Angew. Chem. 2011, 123, 3938 3956; b) S. Chikkali, S. Mecking, Angew. Chem. Int. Ed. 2012, 51, 5802 5808; Angew. Chem. 2012, 124, 59025909.

[2] a) D. Quinzler, S. Mecking, Angew. Chem. Int. Ed. 2010, 49, 4306 4308; Angew. Chem. 2010, 122, 4402 4404; b) F. Stempfle, D. Quinzler, I. Heckler, S. Mecking, Macromolecules 2011, 44, 4159 4166; c) C. Vilela, A. J. D. Silvestre, M. A. R. Meier, Macromol. Chem. Phys. 2012, 213, 2220 2227; d) H. Mutlu, R. Hofsäß, R. E. Montenegro, M. A. R. Meier, RSC Adv. 2013, 3, 4927 4934; e) F. Stempfle, B. Ritter, R. Mülhaupt, S. Mecking, Green Chem. 2014, 16, 20082014.

[3] a) S. Chikkali, S. Mecking, Macromol. Rapid Commun. 2012, 33, 1126 1129; b) P. Ortmann, I. Heckler, S. Mecking, Green Chem. 2014, 16, 18161827.

[4] a) S. Picataggio, T. Rohrer, K. Deanda, D. Lanning, R. Reynolds, J. Mielenz, L. D. Eirich, Nat. Biotechnol. 1992, 10, 894 898; b) U. Schörken, P. Kem pers, Eur. J. Lipid Sci. Technol. 2009, 111, 627 645; c) W. Lu, J. E. Ness, W. Xie, X. Zhang, J. Minshull, R. A. Gross, J. Am. Chem. Soc. 2010, 132, 1545115455.

[5] a) M. B. Dinger, J. C. Mol, Adv. Synth. Catal. 2002, 344, 671 677; b) A. Behr, D. Obst, A. Westfechtel, Eur. J. Lipid Sci. Technol. 2005, 107, 213 219. 
[6] a) W. Clegg, G. R. Eastham, M. R. J. Elsegood, R. P. Tooze, X. L. Wang, K Whiston, Chem. Commun. 1999, 1877 1878. For a prior report on the coordination chemistry of dtbpx: b) N. Carr, B. J. Dunne, A. G. Orpen, J. L. Spencer, J. Chem. Soc. Chem. Commun. 1988, 926928.

[7] C. Jiménez Rodriguez, G. R. Eastham, D. J. Cole Hamilton, Inorg. Chem Commun. 2005, 8, 878881

[8] a) G. Walther, J. Deutsch, A. Martin, F. E. Baumann, D. Fridag, R. Franke, A. Köckritz, ChemSusChem 2011, 4, 1052 1054; b) M. R. L. Furst, R Le Goff, D. Quinzler, S. Mecking, C. H. Botting, D. J. Cole Hamilton, Green Chem. 2012, 14, 472477.

[9] P. Roesle, C. J. Dürr, H. M. Möller, L. Cavallo, L. Caporaso, S. Mecking, J. Am. Chem. Soc. 2012, 134, 1769617703.

[10] a) A. Ehrentraut, A. Zapf, M. Beller, Synlett 2000, 2000, 1589 1592; b) A. Zapf, A. Ehrentraut, M. Beller, Angew. Chem. Int. Ed. 2000, 39, 4153 4155; Angew. Chem. 2000, 112, 4315 4317; c) A. Ehrentraut, A. Zapf, M. Beller, J. Mol. Catal. A 2002, 182 183, 515 523; d) A. Ehrentraut, A Zapf, M. Beller, Adv. Synth. Catal. 2002, 344, 209 217; e) A. Köllhofer, T. Pullmann, H. Plenio, Angew. Chem. Int. Ed. 2003, 42, 1056 1058; Angew. Chem. 2003, 115, 1086 1088; f) R. J. Lundgren, A. Sappong Kumanku mah, M. Stradiotto, Chem. Eur. J. 2010, 16, 1983 1991; g) A. Aranyos, D. W. Old, A. Kiyomori, J. P. Wolfe, J. P. Sadighi, S. L. Buchwald, J. Am Chem. Soc. 1999, 121, 4369 4378; h) J. R. Castanon, N. Sano, M. Shiot suki, F. Sanda, ACS Macro Lett. 2014, 3, 5154.

[11] a) B. Punji, T. J. Emge, A. S. Goldman, Organometallics 2010, 29, 2702 2709; b) J. R. Goerlich, J. v. Weiss, P. G. Jones, R. Schmutzler, Phosphorus Sulfur 1992, 66, 223 243; c) H. Neumann, A. G. Sergeev, M. Beller, Angew. Chem. Int. Ed. 2008, 47, 4887 4891; Angew. Chem. 2008, 120, 4965 4969; d) A. G. Sergeev, A. Spannenberg, M. Beller, J. Am. Chem. Soc. 2008, 130, 1554915563.
[12] G. R. Eastham, P. A. Cameron, R. P. Tooze, K. J. Cavell, P. G. Edwards, D. L. Coleman, (Lucite International UK Limited) WO 2004/014552A1.

[13] Typical composition: $92.5 \%$ methyl oleate (18:1); $2.5 \%$ methyl linoleate $(18: 2) ; 2.5 \%$ methyl palmitate $(16: 0) ; 1.5 \%$ methyl stearate $(18: 0) ; 1.0 \%$ methyl esters of longer chain ( $>\mathrm{C} 18)$ fatty acids.

[14] Note that small amounts of $\left[\mathrm{Ph}_{3} \mathrm{PCH}_{2} \mathrm{OH}\right]^{+}(\mathrm{OTf})$ are formed $\left(\delta^{31} \mathrm{P}\right.$ : $\sin$ glet at $17.1 \mathrm{ppm}$ )

[15] The opening angle describes a cone at the metal center, which is de fined by the space left open by the diphosphine not occupied by any of its atoms. It comprises twice the half cone angle as defined in: J. T. Christl, P. Roesle, F. Stempfle, P. Wucher, I. Göttker Schnetmann, G. Müller, S. Mecking, Chem. Eur. J. 2013, 19, 1713117140.

[16] a) K. Y. Ghebreyessus, R. J. Angelici, Organometallics 2006, 25, 3040 3044; b) L. A. van der Veen, P. C. J. Kamer, P. W. N. M. van Leeuwen Angew. Chem. Int. Ed. 1999, 38, 336 338; Angew. Chem. 1999, 111, 349 351; c) D. Selent, D. Hess, K. D. Wiese, D. Röttger, C. Kunze, A. Börner, Angew. Chem. Int. Ed. 2001, 40, 1696 1698; Angew. Chem. 2001, 113, 17391741.

[17] a) Y. Yuki, K. Takahashi, Y. Tanaka, K. Nozaki, J. Am. Chem. Soc. 2013, 135, 1739317400 ; b) R. P. J. Bronger, J. P. Bermon, J. Herwig, P. C. J. Kamer, P. W. N. M. van Leeuwen, Adv. Synth. Catal. 2004, 346, 789 799; c) H. Klein, R. Jackstell, K. D. Wiese, C. Borgmann, M. Beller, Angew. Chem. Int. Ed. 2001, 40, 3408 3411; Angew. Chem. 2001, 113, 35053508. 